\title{
COMMENTARY
}

\section{Glucocorticoid activity, inactivity and the osteoblast}

\author{
M S Cooper, M Hewison and P M Stewart \\ Department of Medicine, University of Birmingham, Queen Elizabeth Hospital, Edgbaston, Birmingham B15 2TH, UK \\ (Requests for offprints should be addressed to P M Stewart; Email: P.M.Stewart@bham.ac.uk)
}

\section{Introduction}

Although excess circulating glucocorticoids have detrimental effects on bone health, the processes underlying these effects are not well understood. We review what is currently known about the effects of glucocorticoids on osteoblast proliferation and differentiation, with particular emphasis on osteoblast expression of glucocorticoid metabolic enzymes as a mechanism for regulating corticosteroid activity in bone.

The adverse effects on bone of increased circulating concentrations of endogenous glucocorticoids have been recognised since Harvey Cushing's original description of Cushing's disease (Cushing 1912). The increasing use of synthetic glucocorticoids for inflammatory diseases has increased the pressure to understand, and ultimately modify, the processes underlying their deleterious effects on bone. The clinical impact of the problem is reflected both by a doubling of the overall fracture risk in patients taking prednisolone $(7.5 \mathrm{mg}$ for 6 months) and the development of low bone mineral density in $50 \%$ of patients taking higher doses of glucocorticoid (Eastell 1995). Several mechanisms have been proposed for these effects, including reduction in endogenous sex steroid production, decreased muscle mass, and altered gastrointestinal and renal calcium handling causing secondary hyperparathyroidism (Canalis 1996). However, it appears increasingly likely that the most important effect of glucocorticoids is to alter the proliferation and differentiation of cells of the osteoblast lineage. Bone formation in vivo is clearly a complex dynamic process, involving the actions of multiple morphogens, growth factors and hormones. Glucocorticoids could affect any part of the differentiation pathway from initial skeletal patterning and mesoderm induction, commitment of primitive multipotent mesodermal progenitor cells to the osteoblast lineage, or the proliferation and differentiation of preosteoblasts through to mature osteoblasts, to bone-lining cells and osteocytes (Fig. 1). All these stages are likely to occur in normal bone turnover and during fracture healing. For each of these stages, the effects of glucocorticoids, their mechanisms of action and, equally important, the reasons for their lack of action, upon other osteoblasts within the bone microenvironment require explanation. These are outlined in the following review, with particular emphasis on osteoblast expression of glucocorticoid metabolic enzymes as a mechanism for regulating steroid activity in bone.

\section{Glucocorticoids and the commitment of multipotent mesodermal cells to the osteoblast lineage}

Although the effects of glucocorticoids on the formation and proliferation of the earliest osteoblast progenitors potentially have the greatest consequences for the ultimate integrity of bone tissue, remarkably little is known about these processes. Glucocorticoids exert a permissive effect in vitro on cultures of marrow stromal and osteoblast cells. They also affect bone morphogenetic protein expression and can interact with bone-specific nuclear transcription factors.

Glucocorticoids increase the number and size of bone nodules formed in primary bone cell cultures (Cheng et al. 1994). This appears to be due to stimulation of a distinct subset of glucocorticoid-sensitive progenitors. It is not yet clear whether these cells are relatively more primitive or more mature, but osteogenic differentiation in marrow stromal, rather than osteoblast, cultures is even more dependent on the effects of glucocorticoids (Bellows et al. 1990), suggesting that it is the earlier progenitors that are stimulated. The properties of this subset of cells that explain their sensitivity to glucocorticoids remain unknown, as do those that explain the insensitivity of the other cells within the culture.

A potential mechanism for these effects is glucocorticoid modulation of expression and action of bone morphogenetic proteins (BMPs). BMPs are secreted polypeptides, many of which can induce cartilage and bone formation when injected subcutaneously or intramuscularly. Most are members of the transforming growth factor (TGF) $\beta$ superfamily, bind to specific cell-surface BMP receptors and alter gene expression by phosphorylating Smad proteins (specifically Smad1 and Smad5) (Sakou 1998). BMPs-2 and -4 cause a dose-dependent differentiation 


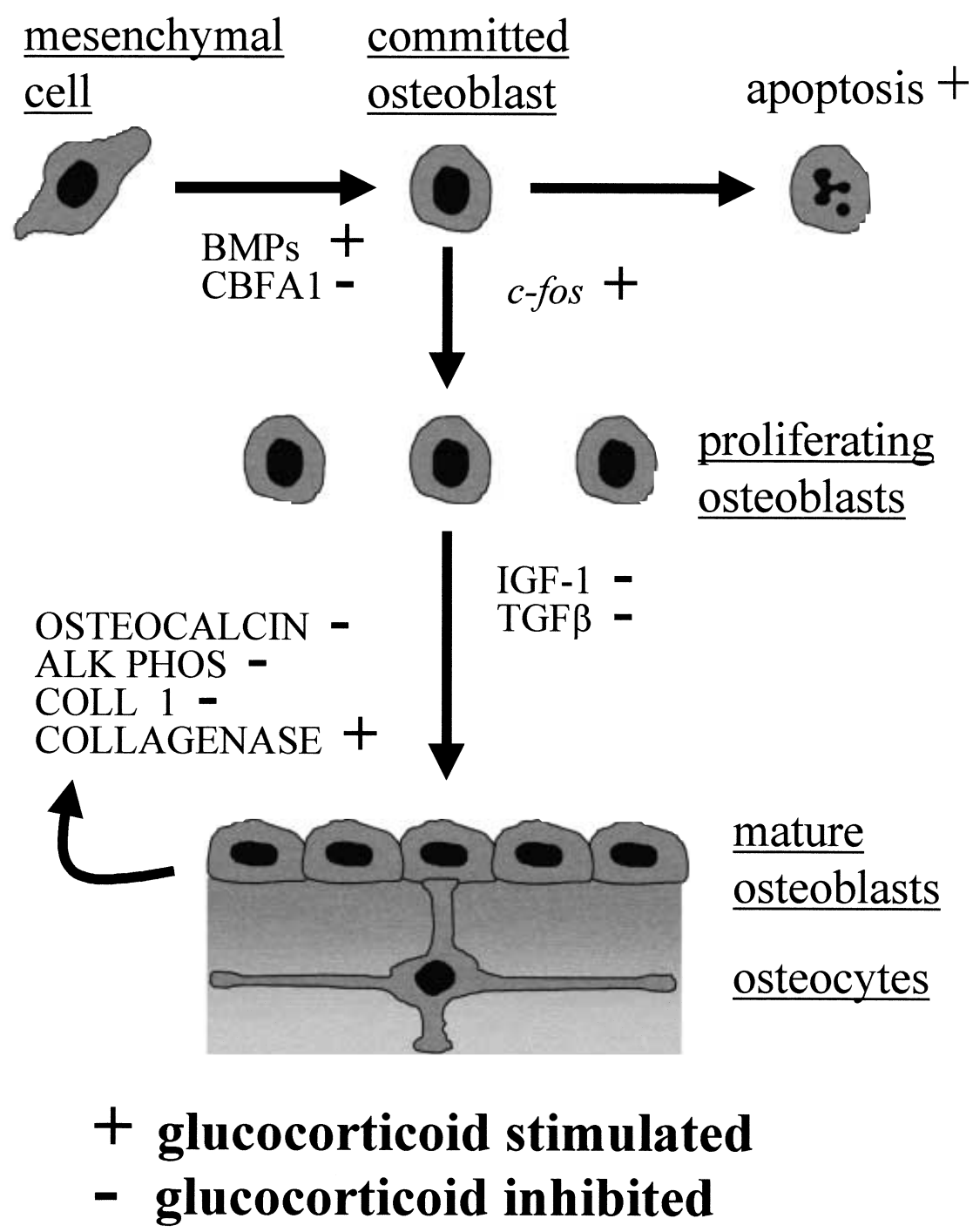

Figure 1 Regulation of proliferation, differentiation and function of cells of the osteoblast lineage by stage-specific factors. Glucocorticoids appear to have actions (stimulatory +, inhibitory -) on all these regulatory factors. ALK PHOS, alkaline phosphatase; COLL, collagen.

of mouse mesodermal progenitor cell lines to cartilage and bone, and BMP-2 promotes differentiation of cells representing early differentiated osteoblasts. Recombinant human BMP-2 has been successfully used as an adjuvant to bone grafting procedures in experimental animals, whereas BMP-6 potently increases bone nodule formation in vitro and ectopic bone formation in vivo when produced by tumours. Glucocorticoids and BMP-2 have been shown to exert a synergistic induction of osteoblast differentiation in both marrow cell cultures (Rickard et al. 1994) and a fetal rat calvarial cell culture model (Boden et al. 1996). Glucocorticoids also increase the expression of both BMP-6 protein and mRNA several-fold in the calvarial model. Similarly, antisense BMP-6 treatment can partly block glucocorticoid-induced differentiation (Boden et al. 1997). This suggests that glucocorticoid modulation of BMP expression and action is likely to be an important factor in regulating osteoblastic differentiation.

In addition to BMPs, bone formation is critically dependent upon the expression of the nuclear transcription factor CBFA1 (core binding factor-1) (Komori et al. 1997). Homozygous disruption of the CBFA1 locus in mice leads to normal cartilage formation, but an absence of bone tissue. Expression of CBFA1 is upregulated by BMP-2 and the normal expression of bone specific markers in 
BMP-2-treated marrow cultures is blocked in CBFA1-/mice. Glucocorticoids (both cortisol and dexamethasone) have been shown to suppress the effects of CBFA1 on TGF $\beta$ receptor 1 promoter activity (Chang et al. 1998) possibly by decreasing CBFA1 mRNA stability. Thus glucocorticoids can suppress an effect that would be expected to be anabolic to bone. The combination of effects on BMPs and CBFA1 implies that glucocorticoids can have opposing effects on the induction of osteoblast commitment, inducing and potentiating the effects of BMPs on the one hand whilst suppressing the effects of CBFA1 on the other. The resultant effect in vivo remains to be determined, as does the importance of continued CBFA1 expression in committed osteoblasts and whether the suppressive effect of glucocorticoids continues.

\section{Glucocorticoids and proliferation, differentiation and function of committed osteoblasts}

Glucocorticoids affect both proliferation and differentiation of osteoblasts, and their effects are often biphasic within the same system. Most studies have focused on in vitro systems. In cultured fetal rat calvariae, physiological concentrations of cortisol have a stimulatory effect on collagen synthesis at $24 \mathrm{~h}$, whereas supraphysiological concentrations have an inhibitory effect at 48-96 h. The stimulatory effects appear to be due to increased osteoblastic differentiation, whereas the inhibitory effects result from a reduction in proliferation (Gronowicz et al. 1994). Direct evidence for changes in proliferation and differentiation of osteoblasts in vivo is sparse. One study showed that bone marrow cultures from mice treated with pharmacological concentrations of glucocorticoids showed decreased formation of fibroblast colony-forming units, possibly indicating a depletion of osteogenic precursors (Simmons et al. 1990). There is clearly a need for better in vivo model systems.

Glucocorticoids affect several osteoblast-specific and osteoblast-related gene products, including protooncogenes, collagens and collagenases, bone matrix components and potential growth factors. The earliest glucocorticoid mediated effect seen in vitro is a rapid transient increase in the proto-oncogene, c-fos. Expression of c-fos is greatest during osteoblast development, and overexpression of $\mathrm{c}-\mathrm{fos}$ in transgenic mice leads to the development of multiple osteoblastic and chondrogenic tumours (Grigoriadis et al. 1993), suggesting an important role in the regulation of osteoblast differentiation. This effect is not seen with overexpression of other protooncogenes, such as c-jun. The c-fos is an important component of activator protein-1 (AP-1) trans-regulatory complex, which can influence expression of many osteoblast related genes. In contrast to the stimulatory effect on c-fos, glucocorticoids have an inhibitory effect on AP-1mediated activity in many systems, an effect believed to occur through direct protein-protein interactions between AP-1 and the glucocorticoid receptor. As with many of these gene products, the relevance of glucocorticoidinduced c-fos expression or AP-1 inhibition in bone in vivo is unclear.

Type 1 collagen is the major constituent of bone matrix, and glucocorticoids have important effects on type 1 collagen expression. There is a decrease in both protein and mRNA levels in rat and human osteoblasts and in rat calvarial cultures treated with dexamethasone (Delany et al. 1994). In addition, glucocorticoids may alter expression of enzymes that degrade collagen. Collagenase is expressed in normal human osteoblasts in vivo (Bord et al. 1996) and expression in cultured rat calvarial cells in vitro is stimulated by glucocorticoids (Delany et al. 1995). Osteoblast-mediated collagenase activity has been implicated in the removal of unmineralised osteoid that is lining bone surfaces (Chambers \& Fuller 1985). This action may initiate the bone remodelling cycle, and excess stimulation of this activity by glucocorticoid could have a deleterious effect on bone.

Glucocorticoids also affect the non-collagenous components of bone matrix. Osteocalcin is the most abundant of these, although its function remains unclear. In most osteoblastic systems studied, glucocorticoids inhibit expression of osteocalcin mRNA and protein, an effect that also occurs in vivo. This effect is believed to occur by binding of glucocorticoid receptor to a response element in a region overlapping a TATA box in the osteocalcin promoter (Stromstedt et al. 1991). A further important marker of osteoblastic differentiation and growth is alkaline phosphatase. Alkaline phosphatase expression is usually upregulated by glucocorticoids in vitro, as a result of a direct transcriptional effect. In vivo, however, glucocorticoids cause suppression of alkaline phosphatase in mature osteoblasts. As with many glucocorticoid responses, the reason for stimulation in one context and suppression in another remains unclear.

Glucocorticoids also affect osteoblasts through changes in the concentration of, or sensitivity to, other growth factors or hormones. This has been investigated most extensively for insulin-like growth factor (IGF)-1 and TGF $\beta$. IGF-1 is mitogenic for osteoblasts and anabolic for bone. Glucocorticoids decrease expression of IGF-1 mRNA expression in rat tibia, fetal rat calvarial cultures and primary osteoblastic cells (Chen et al. 1991). They have complicated and diverse actions on IGF binding proteins (IGFBPs), but appear to reduce the concentration of several IGFBPs (Canalis 1996). Glucocorticoids may also interfere with IGF-1 signalling at a post-receptor level. TGF $\beta$ is another anabolic growth factor for bone. Glucocorticoids decrease the stimulatory effect of TGF $\beta$ on fetal rat osteoblastic cells and increase the binding of TGF $\beta$ to betaglycan (Centrella et al. 1991), the lowaffinity TGF $\beta$ receptor that may cause a sequestration of TGF $\beta$ and therefore a decrease in activity. In contrast, 


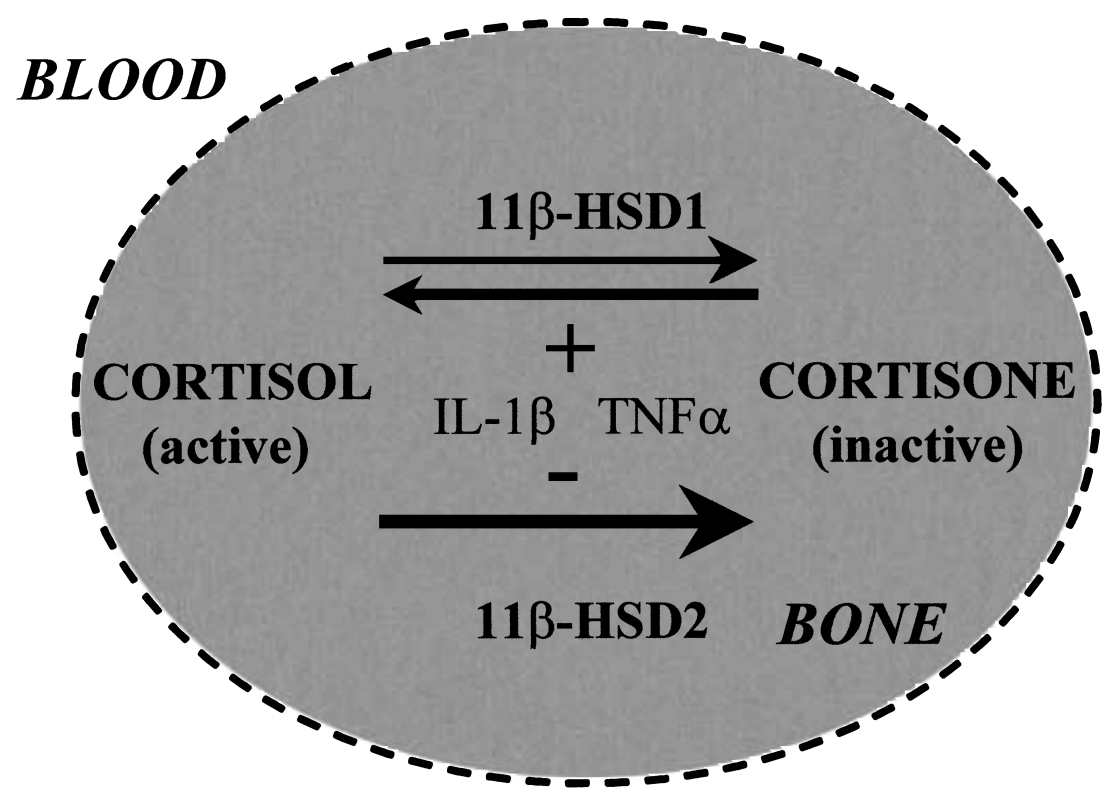

Figure 2 Schematic illustration of the role of $11 \beta$-HSD enzymes in the osteoblast. Glucocorticoid hormone action is likely to be dependent on the balance between intracellular glucocorticoid production and inactivation. This balance is likely to be regulated by differentiation stage and factors present within the bone microenvironment. IL, interleukin.

glucocorticoids increase the formation of active TGF $\beta$ from latent TGF $\beta$ (Oursler et al. 1993). The functional consequences of these changes in the IGF-1 and TGF $\beta$ axes in vivo are unknown.

In addition to these effects on proliferation, differentiation and function of osteoblasts, the role of glucocorticoids in the induction or inhibition of apoptosis is likely to be important. An increase in the rate of apoptosis of both osteoblasts and osteocytes in adult mice treated with prednisolone has been demonstrated (Weinstein et al. 1998) but, in contrast, glucocorticoids were protective against apoptosis induced in primary human osteoblasts by activated peripheral blood mononuclear cells (Nakashima et al. 1998). These opposing results suggest that the sensitivity of the osteoblast to the action of glucocorticoids is critically dependent on its state of differentiation.

\section{Mechanisms for alteration of osteoblast sensitivity to glucocorticoids}

Several mechanisms have been proposed whereby the cellular sensitivity to glucocorticoids can be altered. These include changes in affinity or concentration of glucocorticoid receptor, alteration in the ability of the receptor to dissociate from heat shock proteins, undergo phosphorylation or translocate to the cell nucleus, and modulation of the interaction of the glucocorticoid receptor with glucocorticoid response elements, other transcription factors or the basal transcription machinery (Bamberger et al. 1996). In the osteoblast, these mechanisms have not been studied in any detail. At a pre-receptor level, the functional importance of intracellular glucocorticoid metabolism in several tissues such as kidney (Stewart et al. 1996), liver (Kotelevtsev et al. 1997) and omental fat (Bujalska et al. 1997) has recently been demonstrated. 11ßHydroxysteroid dehydrogenase (11 $\beta-\mathrm{HSD})$, by catalysing the interconversion of hormonally active cortisol to inactive cortisone, is established in these tissues as an important modulator of corticosteroid hormone action. Two isozymes of $11 \beta-H S D, 11 \beta-H S D 1$ and $11 \beta-H S D 2$ have, respectively, been shown to regulate glucocorticoid and mineralocorticoid hormone action (White et al. 1997). $11 \beta-H S D 1$ is a low-affinity, bi-directional, NADPHdependent enzyme that has a greater affinity for cortisone than for cortisol. In contrast, $11 \beta-H S D 2$ is a high-affinity, NAD-dependent dehydrogenase, inactivating cortisol to cortisone. In addition to endogenous glucocorticoids, the synthetic glucocorticoids, prednisolone and dexamethasone, are substrates for $11 \beta-H S D$, though with reduced affinity compared with cortisol and cortisone. We have recently demonstrated the presence of $11 \beta-H S D s$ in human osteoblasts: $11 \beta-H S D 1$ in osteoblast primary cultures (Bland et al. 1999), cell lines and normal adult bone (Cooper et al. 1998); 11ß-HSD2 in osteosarcoma cell lines (Bland et al. 1999) and normal fetal bone (Condon et al. 1998). 11ß-HSD expression and activity are regulated by factors likely to be present in the bone microenvironment 
(Cooper et al. 1999), notably tumour necrosis factor- $\beta$ and interleukin-1 $\beta$, but not interleukin-6 or TGF $\beta$. Furthermore, $11 \beta-H S D$ s in bone demonstrate several unusual, 'unique' features. In contrast to other tissues, in bone $11 \beta-H S D 1$ functions predominantly as a dehydrogenase, suggesting a 'protective' role in adult bone - thus the presence of these enzymes in osteoblasts may be an important determinant of glucocorticoid activity or inactivity (Fig. 2). The kinetic properties of these enzymes could also account for some of the biphasic responses seen with glucocorticoids. In addition, $11 \beta-H S D 2$ in fetal bone co-localises with both glucocorticoid receptor and mineralocorticoid receptor, suggesting a possible role for glucocorticoid-mediated signalling via the latter receptor in normal bone physiology or development.

\section{Summary}

Glucocorticoids clearly regulate several crucial determinants of osteoblast differentiation, proliferation and function. These effects are complex and at times opposing, depending upon dose and stage of osteoblast differentiation. In addition to improving our understanding of glucocorticoid action, we are now increasingly aware of important factors that regulate glucocorticoid 'inactivity' within osteoblasts.

In keeping with other peripheral target tissues, the expression of $11 \beta-H S D$ isozymes within human bone suggests that corticosteroid hormone action is modulated at a pre-receptor level. Further studies are required to define the regulation of $11 \beta-\mathrm{HSD}$ within human osteoblasts at varying stages of differentiation, but the manipulation of $11 \beta$-HSD within bone itself may, in the future, offer a novel therapeutic approach in modulating glucocorticoid 'activity' or 'inactivity' in bone.

\section{Acknowledgements}

Mark S Cooper is a Medical Research Council Clinical Research Fellow and Paul M Stewart is an MRC Senior Clinical Fellow.

\section{References}

Bamberger CM, Schulte HM \& Chrousos GP 1996 Molecular determinants of glucocorticoid receptor function and tissue sensitivity to glucocorticoids. Endocrine Reviews 17 245-261.

Bellows CG, Heersche JNM \& Aubin JE 1990 Determination of the capacity for proliferation and differentiation of osteoprogenitor cells in the presence and absence of dexamethasone. Developmental Biology 140 132-138.

Bland R, Worker CA, Noble BS, Eyre LJ, Bujalska IJ, Sheppard MC, Stewart PM \& Hewison M 1999 Characterization of $11 \beta$ hydroxysteroid dehydrogenase activity and corticosteroid receptor expression in human osteoblastic cells. Journal of Endocrinology 161 $455-464$.
Boden SD, McCuaig K, Hair G, Racine M, Titus L, Wozney JM \& Nanes MS 1996 Differential effects and glucocorticoid potentiation of bone morphogenetic protein action during rat osteoblast differentiation in vitro. Endocrinology 137 3401-3407.

Boden SD, Hair G, Titus L, Racine M, McCuaig K, Wozney JM \& Nanes MS 1997 Glucocorticoid-induced differentiation of fetal rat calvarial osteoblasts is mediated by bone morphogenetic protein- 6 . Endocrinology 138 2820-2828.

Bord S, Horner A, Hembry RM, Reynolds JJ \& Compston JE 1996 Production of collagenase by human osteoblasts and osteoclasts in vivo. Bone 19 35-40.

Bujalska IJ, Kumar S \& Stewart PM 1997 Does central obesity reflect 'Cushing's disease of the omentum'? Lancet 349 1210-1213.

Canalis E 1996 Clinical review 83. Mechanisms of glucocorticoid action in bone: implications to glucocorticoid-induced osteoporosis. Journal of Clinical Endocrinology and Metabolism 81 3441-3447.

Centrella M, McCarthy TL \& Canalis E 1991 Glucocorticoid regulation of transforming growth factor- $\beta 1$ activity and binding in osteoblast-enriched cultures from fetal rat cone. Molecular and Cellular Biology 11 4490-4496.

Chambers TJ \& Fuller K 1985 Bone cells predispose bone surfaces to resorption by exposure of mineral to osteoclastic attack. Journal of Cell Science 76 155-165.

Chang DJ, Ji C, Kim K, Casinghino S, McCarthy TL \& Centrella M 1998 Reduction in transforming growth factor $\beta$ receptor 1 expression and transcription factor $\mathrm{CBFa} 1$ on bone cells by glucocorticoid. Journal of Biological Chemistry 273 4892-4896.

Chen TL, Chang LY, Bates RL \& Perlman AJ 1991 Dexamethasone and 1,25-dihydroxyvitamin D3 modulation of insulin-like growth factor-binding proteins in rat osteoblast-like cell cultures. Endocrinology 128 73-80.

Cheng SL, Yang JW, Rifas L, Zhang S \& Avioli LV 1994 Differentiation of human bone marrow osteogenic stromal cells in vitro: induction of the osteoblast phenotype by dexamethasone. Endocrinology 134 277-286.

Condon J, Gosden C, Gardener D, Nickson P, Hewison M, Howie AJ \& Stewart PM 1998 Expression of type 2 11ß-hydroxysteroid dehydrogenase and corticosteroid hormone receptors in early fetal life. Journal of Clinical Endocrinology and Metabolism 83 4490-4497.

Cooper MS, Ricketts ML, Verhaeg JM, Mangham CD, Hewison M \& Stewart PM 1998 Expression and activity of $11 \beta$-hydroxysteroid dehydrogenases in human bone and cartilage. Journal of Endocrinology 159 (Suppl) P3.

Cooper MS, Hewison M \& Stewart PM 1999 Cytokine inhibition of 11/-hydroxysteroid dehydrogenase type 2 in osteoblasts: a novel autocrine anti-inflammatory mechanism. Journal of Endocrinology 160 (Suppl) P225.

Cushing HW 1912 The Pituitary Body and its Disorders. Philadelphia: JB Lippincott.

Delany AM, Dong Y \& Canalis E 1994 Mechanisms of glucocorticoid action in bone cells. Journal of Cellular Biochemistry 56 295-302.

Delany AM, Jeffrey JJ, Rydziel S \& Canalis E 1995 Cortisol increases interstitial collagenase expression in osteoblasts by posttranscriptional mechanisms. Journal of Biological Chemistry $\mathbf{2 7 0}$ 26607-26612.

Eastell R 1995 Management of corticosteroid-induced osteoporosis. Journal of Internal Medicine 237 439-447.

Grigoriadis AE, Schellander K, Wang ZQ \& Wagner EF 1993 Osteoblasts are target cells for transformation in c-fos transgenic mice. Journal of Cell Biology 122 685-701.

Gronowicz GA, Fall PM \& Raisz LG 1994 Prostaglandin E2 stimulates preosteoblast replication: an autoradiographic study in cultured fetal rat calvariae. Experimental Cell Research 212 314-320.

Komori T, Yagi H, Nomura S, Yamaguchi A, Sasaki K, Deguchi K, Shimizu Y, Bronson RT, Gao YH, Inada M, Sato M, Okamoto R, Kitamura Y, Yoshiki S \& Kishimoto T 1997 Targeted disruption of Cbfa1 results in a complete lack of bone formation owing to maturational arrest of osteoblasts. Cell $89755-764$ 
Kotelevtsev Y, Holmes MC, Burchell A, Houston PM, Schmoll D, Jamieson P, Best R, Brown R, Edwards CRW, Seckl JR \& Mullins JJ 1997 11 $\beta$-Hydroxysteroid dehydrogenase type 1 knockout mice show attenuated glucocorticoid-inducible responses and resist hyperglycemia on obesity or stress. Proceedings of the National Academy of Sciences of the USA 94 14924-14929.

Nakashima T, Sasaki H, Tsuboi M, Kawakami A, Fujiyama K, Kiriyama T, Eguchi K, Ichikawa M \& Nagataki S 1998 Inhibitory effect of glucocorticoid for osteoblast apoptosis induced by activated peripheral blood mononuclear cells. Endocrinology 139 2032-2040.

Oursler MJ, Riggs BL \& Conover CA 1993 Glucocorticoid-induced activation of latent transforming growth factor- $\beta$ by normal human osteoblast-like cells. Endocrinology 133 2187-2196.

Rickard DJ, Sullivan TA, Shenker BJ, Leboy PS \& Kazhdan I 1994 Induction of rapid osteoblast differentiation in rat bone marrow stromal cell cultures by dexamethasone and BMP-2. Developmental Biology 161 218-228.

Sakou T 1998 Bone morphogenetic proteins: from basic studies to clinical approaches. Bone 22 591-603.

Simmons DJ, Kidder L \& Thomas M 1990 Effect of cortisone on cells at the bone-marrow interface. Calcified Tissues International 46 327-332.
Stewart PM, Krozowski ZS, Gupta A, Milford DV, Howie AJ, Sheppard MC \& Whorwood CB 1996 Hypertension in the syndrome of apparent mineralocorticoid excess due to mutation of the $11 \beta$-hydroxysteroid dehydrogenase type 2 gene. Lancet $\mathbf{3 4 7}$ $88-91$.

Stromstedt PE, Poellinger L, Gustafsson JA \& Carlstedt-Duke J 1991 The glucocorticoid receptor binds to a sequence overlapping the TATA box of the human osteocalcin promoter: a potential mechanism for negative regulation. Molecular and Cell Biology 11 3379-3383.

Weinstein RS, Jilka RL, Parfitt M \& Manolagas SC 1998 Inhibition of osteoblastogenesis and promotion of apoptosis of osteoblasts and osteocytes by glucocorticoids. Journal of Clinical Investigation 102 274-282.

White PC, Mune T \& Agarwal AK 1997 11ß-Hydroxysteroid dehydrogenase and the syndrome of apparent mineralocorticoid excess. Endocrine Reviews 18 135-156.

Received 15 March 1999

Accepted 8 June 1999 